\title{
Electromagnetic Stirring versus ECAP: Morphological Comparison of Al-Si-Cu Alloys to Make the Microstructural Refinement for Use in SSM Processing
}

\author{
Luis Vanderlei Torres, Luis Fernando Torres, and Eugênio José Zoqui \\ Materials and Manufacturing Engineering Department (MMED), Faculty of Mechanical Engineering (FEM), \\ University of Campinas (UNICAMP), 13083-860 Campinas, SP, Brazil
}

Correspondence should be addressed to Luis Vanderlei Torres; torres@fem.unicamp.br

Received 17 July 2016; Revised 17 August 2016; Accepted 20 September 2016

Academic Editor: Pavel Lejcek

Copyright (C) 2016 Luis Vanderlei Torres et al. This is an open access article distributed under the Creative Commons Attribution License, which permits unrestricted use, distribution, and reproduction in any medium, provided the original work is properly cited.

\begin{abstract}
This work evaluates the morphological evolution at the semisolid state of the Al-4.0wt $\% \mathrm{Si}-2.5 \mathrm{wt} \% \mathrm{Cu}$ alloy produced by direct chill casting under electromagnetic stirring (EMS) and by one equal channel angular pressing (ECAP) pass. The ECAP emerged as a promising technique capable of reduction and homogeneous metals microstructure imposing large deformations occurs in a matrix that contains two channels of the same cross-sectional area and forms an angle of $120^{\circ}$. The materials were submitted to reheating treatment in condition of $60 \%$ solid fraction at treatment times of 0,30 , and $90 \mathrm{~s}$. Comparing the two cases, we have the presented ECAP process that had an excellent response to the recovery and recrystallization mechanisms, and refined microstructures ideal for thixoforming were produced. Primary particle sizes of about $45 \mu \mathrm{m}$ and grain sizes of about $75 \mu \mathrm{m}$ and a circularity shape factor of more than 0.60 were obtained. The low silicon alloy, $\mathrm{Al}-4.0 \mathrm{wt} \% \mathrm{Si}-2.5 \mathrm{wt} \% \mathrm{Cu}$, presented excellent refinement when processed via equal channel angular pressing, presenting good morphological stability at the semisolid state, without significant changes in size or shape of the solid particles. This fully globular structure is favourable for thixoforming processes.
\end{abstract}

\section{Introduction}

The semisolid material (SSM) processing is an alternative route to conventional metal shaping processes such as casting and forging; the advantages of SSM processing include high energy and production efficiency, low forming loads, nearnet-shape capability, and reduced porosity. The automotive industry in the last decade has played a leading role in the development of new processes for manufacturing parts using semisolid materials. The use of aluminium in automobiles, primarily in the form of castings, has increased significantly due to the need to produce parts with high mechanical strength, low weight, and high reliability. The thixoforming process is nothing more than the semisolid processing of alloys in which two phases coexist: a solid and a liquid phase [1-3].

Several routes have been tested to produce these nondendritic structures [1-7]. One of the most promising routes is the raw material production via equal channel angular pressing (ECAP); the deformation ECAP occurs in a matrix containing two channels of the same cross-sectional area. Samples that pass through these channels undergo deformation by simple shear. As the cross section of the sample remains approximately constant, the process can be repeated many times allowing for controlling the microstructure and thus the final properties of the materials $[8,9]$. It is known that $\mathrm{Al}-\mathrm{Si}-\mathrm{Cu}$ alloy content of low silicon does not have a fine structure by ECAP process [10], but alloys with the same content and greater than $5 \mathrm{wt} \% \mathrm{Si}$ have large refinement of the microstructure, with grain sizes/primary globules much lower when compared with the electromagnetic stirring [11].

Aluminium alloys used for processing in semisolid state are notably foundry alloys A356 and A357 [12]; thus, the development of new alloys especially designed for use in thixoforming is the new challenge in this area of research. Therefore, this paper aims to evaluate the morphological 

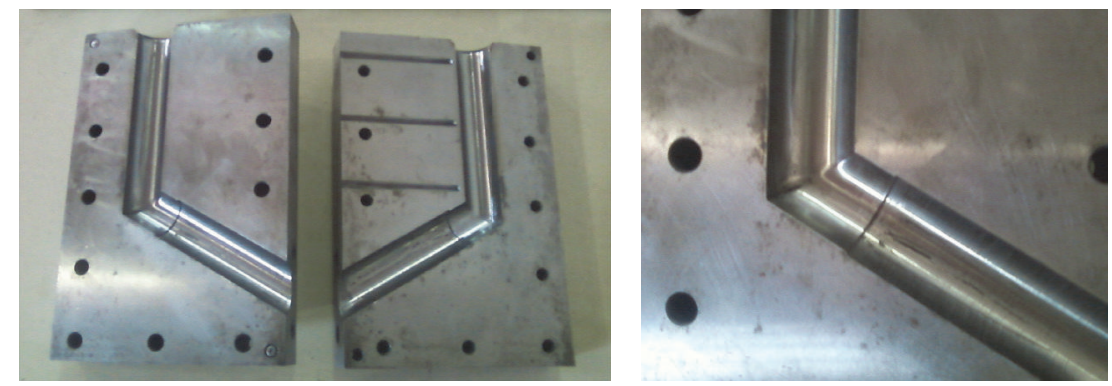

FIGURE 1: Details of the used ECAP die.

TABLE 1: Mass distribution for the preparation of alloy [in $\mathrm{kg}$ ].

\begin{tabular}{lcccc}
\hline Alloy & A356 & Al-cp & Cu-cp & $\begin{array}{c}\text { Grain } \\
\text { refining }\end{array}$ \\
\hline Al-4.0wt\%Si-2.5wt\%Cu & 2.7 & 2.0 & 0.1 & 0.2 \\
\hline
\end{tabular}

evolution at the semisolid state of the $\mathrm{Al}-4.0 \mathrm{wt} \% \mathrm{Si}-2.5 \mathrm{wt} \% \mathrm{Cu}$ alloy produced by direct chill casting under electromagnetic stirring (EMS) and by one equal channel angular pressing (ECAP) pass in terms of microstructural characterization for different conditions of heat treatment by using microscopy, using conventional metallography (black and white), and using polarized metallography (colour) to determine the refinement of the microstructure of alloy $\mathrm{Al}-\mathrm{Si}-\mathrm{Cu}$.

\section{Experimental Procedure}

For the preparation of $5 \mathrm{~kg}$ of the alloy, generating approximately 12 ingots, according to Table 1, the following mass distribution was reached. The $\mathrm{Cu}-\mathrm{cp}$ content was increased by approximately $10 \%$ than expected due to the difficulty of copper dissolution into the molten bath.

Table 2 describes the chemical composition of the Al$4.0 \mathrm{wt} \% \mathrm{Si}-2.5 \mathrm{wt} \% \mathrm{Cu}$ alloy produced by electromagnetic stirring combined with grain refinement; approximately $8 \mathrm{~kW}$ of power was used to produce a magnetic field of 13 gauss [3]. The chemical composition was determined via Bill OES optical emission spectrometry. The alloy was produced using A356, commercially pure aluminium (Al-cp), and commercially pure copper (Cu-cp). The A356 alloy was heated to $750^{\circ} \mathrm{C}$ in a $\mathrm{SiC}$ crucible in an electric furnace, and the commercially pure aluminium and commercially pure copper were added and mixed properly. The mixture was kept and held at $750^{\circ} \mathrm{C}$ for about $10 \mathrm{~min}$ and stirred periodically to ensure that it dissolved and homogenized, and finally grain refining $\mathrm{Al}-5.0 \mathrm{wt} \% \mathrm{Ti}-1.0 \mathrm{wt} \% \mathrm{~B}$ was added in order to obtain a nondendritic structure $[3,9]$. Then, each molten alloy was poured at a temperature about $50^{\circ} \mathrm{C}$ above its expected melting temperature into a copper refrigerated mould to produce ingots $250 \mathrm{~mm}$ in length and $30 \mathrm{~mm}$ in diameter; due to errors inherent in processes, casting, and chemical analysis, an acceptable deviation range of $0.30 \mathrm{wt} \% \mathrm{Si}$ and $0.15 w t \% \mathrm{Cu}$ was adopted.
ECAP deformation was performed in a metallic mould with cylindrical channels with cross sections of $30 \mathrm{~mm}$ and $120^{\circ}$ outer angle; Figure 1 shows the details of the used ECAP die. A 50-ton hydraulic press operating at maximum speed of approximately $7 \mathrm{~mm} / \mathrm{s}$ was used to impose a single ECAP pass in ingots lubricated with $\mathrm{MoS}_{2}$ [10]. Before the ECAP process, the ingots $30 \mathrm{~mm}$ in diameter and $150 \mathrm{~mm}$ long were heated to $300^{\circ} \mathrm{C}$ sufficient to prevent surface cracks but also to allow better passage thereof through the ECAP die. According to previous studies, the die must be heated to $100^{\circ} \mathrm{C}$, so that it is avoided that adiabatic heat generated during the extrusion, along the preheating temperature of the ingot, does not reach the material recrystallization temperature.

Heat treatment globularization aims to verify the stability of alloy at high temperatures in order to evaluate the microstructural evolution and correlate these characteristics with the mechanical and rheological properties of these materials. The treatments were carried out in approximately $6 \mathrm{~min}(25 \mathrm{~mm}$ tall $\times 30 \mathrm{~mm}$ diameter samples $)$ in a Norax induction furnace $(25 \mathrm{~kW}, 8 \mathrm{kHz})$ with a heating rate of $80^{\circ} \mathrm{C}$ to $100^{\circ} \mathrm{C} / \mathrm{min}[3,10]$. When the samples reached the temperatures of the $60 \%$ solid fraction, they were held at those temperatures for 0,30 , and $90 \mathrm{~s}$, after which they were cooled in water. The samples produced were characterized by optical microscopy to morphologically evaluate the semisolid state. All the samples were subjected to conventional metallographic (black and white) and polarized metallography (colour) to evaluate their structures. For microstructural characterization by conventional metallographic, the samples were abraded with sandpaper in a particle size of 220, 320, $400,600,800,1200$, and 1500 and polished with diamond paste $1 \mu \mathrm{m}$; after polishing, the samples were etched with hydrofluoric acid ( $\mathrm{HF} 1 \mathrm{~mL}$ and $99 \mathrm{~mL} \mathrm{H}_{2} \mathrm{O}$ ); the attack was performed with total immersion of the sample in the reagent for a period of $10 \mathrm{~s}$. For the microstructure characterization via colour metallography, the same samples used in the B\&W characterization were etched using an electrolytic solution of $2 \% \mathrm{HBF} 4$ under $25 \mathrm{~V}$ for 6 minutes. For image acquisition, we used a Leica DM ILM optical microscope. Polarizing filters were used to obtain colour images of the samples grains, causing grains with the same crystal orientation to exhibit similar colour, facilitating their identification and characterization. For measuring globule size (GLS) in conventional metallography and grain size (GS) in colour metallography, the Heyn intercept method was used as recommended by the 
TABLE 2: Chemical composition of the Al-4.0wt\%Si-2.5wt\%Cu alloy [in wt\%], obtained by optical emission spectrometry.

\begin{tabular}{lcccccccc}
\hline Alloy & $\mathrm{Si}$ & $\mathrm{Cu}$ & $\mathrm{Mg}$ & $\mathrm{Ti}$ & $\mathrm{Fe}$ & $\mathrm{B}$ & $\mathrm{Mn}$ & $\mathrm{Al}$ \\
\hline Al-4.0wt\%Si-2.5wt\%Cu & 3.84 & 2.54 & 0.18 & 0.15 & 0.14 & 0.002 & 0.01 & $\mathrm{Bal}$ \\
\hline
\end{tabular}

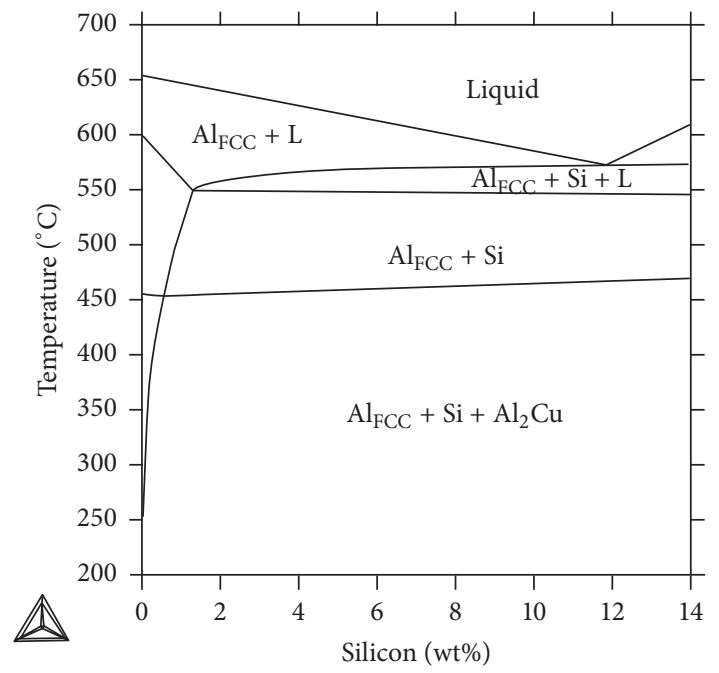

FIGURE 2: Expected phase diagram for the Al-4.0wt $\% \mathrm{Si}-2.5 \mathrm{wt} \% \mathrm{Cu}$ alloy.

ASTM E112 (1996) standard. For the circularity, shape factor (SF) of each sample was used for conventional photographs, ImageJ $1.40 \mathrm{~g}$ software, and the value varies from 0 (for acicular particles) to 1 (a perfectly round sphere). B\&W metallography was used to measure the globule size (GLS) and shape factor (SF) and colour metallography is used to determine the grain size (GS). The Rheocast Quality Index $(\mathrm{RQI}=(\mathrm{GLS} * \mathrm{SF}) / \mathrm{GS})$ gives the relationship of those features where a perfect structure in which a grain is a perfect globule leads to a RQI $=1$.

As described in previous paper [14], this work also used Thermo-Calc ${ }^{\circledR}$ simulation; the percentages of copper, magnesium, iron, and titanium were taken into account, but residual elements, such as manganese, chromium, nickel, and zinc, were not. Thermo-Calc predicts solidus temperature of $525^{\circ} \mathrm{C}$, liquidus temperature of $627^{\circ} \mathrm{C}$, and, for expected $60 \%$ solid fraction, processing temperature of $584^{\circ} \mathrm{C}$. Based on the chemical composition of the alloy obtained by optical emission spectrometry, the expected phase diagram was drawn using the Thermo-Calc software. Figure 2 shows the expected phase diagram taking into account the amount of copper for the $2.5 \mathrm{wt} \% \mathrm{Cu}$. Because of the instability of the eutectic melting (characterized by the competitive growth), the semisolid processing should be done between the solidus temperatures and temperature liquidus. It was realized that, to have the thixoforming process of these hypoeutectic alloys correctly applied, it is necessary to achieve a temperature where $\mathrm{Al}_{\mathrm{FCC}}$ coexists with the liquid rich-silicon; nevertheless, the semisolid behaviour will depend on the remaining solid's morphology and shape.

\section{Results and Discussion}

Figure 3 shows the conventional metallographic of the original microstructure of the $\mathrm{Al}-4.0 \mathrm{wt} \% \mathrm{Si}-2.5 \mathrm{wt} \% \mathrm{Cu}$ alloy produced by EMS and the corresponding microstructure after one ECAP pass for all performed experiments. The original structures rapidly evolve from rosette shape (EMS) or elongated rosettes (ECAP); it is possible to observe that the globule size is severely deformed and the small dendritic branches evolved into a deformed and elongate rosette shape. Figures 4 and 5 show the microstructure (conventional and colour metallography) of the material reheated at temperature of $60 \%$ of solid fraction for times of 0,30 , and $90 \mathrm{~s}$ produced by ECAP, since the alloy produced by electromagnetic stirring has been the subject of studies [3]. Note that the reheating treatment of the ECAPed sample at only $0 \mathrm{~s}$ was enough to produce a fully globular structure, and the maintenance at this temperature during long periods of time (90 s) does not change the structure significantly (i.e., the structure is stable at semisolid range). Note the maintenance of the primary globule/grain size during reheating to the semisolid material range in the treatment time of $0 \mathrm{~s}$ to $90 \mathrm{~s}$. Therefore, the use of ECAP process is suitable for obtaining raw material for thixoforming, since it produces small and fully globular grains.

When the raw material is deformed during the ECAP process, the grains are strained and hardened and strain energy is stored. During the reheating in the semisolid state, energy is released during recovery and recrystallization. As recrystallization involves the nucleation and growth of an entirely new arrangement of crystals, they already have a globular morphology. The heating for recrystallization at temperature lower than solidus temperature achieves, in fact, lower grain size, but the heating up to the semisolid state introduces new mechanisms as coarsening that leads to a bigger grain size, but this new grain is, still, smaller than that produced by EMS [9]. Therefore, the use of the ECAP process is suitable for obtaining raw material for thixoforming, since it produces globular grains. According to Proni et al. [11], using the $\mathrm{Al}-2.0 \mathrm{wt} \% \mathrm{Si}-2.5 \mathrm{wt} \% \mathrm{Cu}$ alloy (low silicon), the values of primary globule/grain size are almost identical for both the procedures tested, EMS and ECAP (i.e., there is no significant improvement using the ECAP process for low silicon alloys, but it is highly recommended for high silicon due to the poor effect of the EMS refinement in terms of grain size and its shape); this is due to the fact that in the aluminium-silicon alloys with low silicon content the effect of stirring is enough to produce the desired globular structure, but with higher silicon content, the results diverge [13]. It is possible to conclude that the use of ECAP is recommended only for high silicon alloys, (> $4 \mathrm{wt} \% \mathrm{Si})$. 
TABLE 3: Microstructural characterization of the Al-4.0wt $\% \mathrm{Si}-2.5 \mathrm{wt} \% \mathrm{Cu}$ alloy.

\begin{tabular}{lcccrr}
\hline & Treatment time $[\mathrm{s}]$ & Globule size $[\mu \mathrm{m}]$ & Circularity & Grain size $[\mu \mathrm{m}]$ & RQI \\
\hline As, cast & & $35 \pm 3$ & $0.43 \pm 0.19$ & $0.20 \pm 0.07$ \\
\hline \multirow{3}{*}{ EMS } & 0 & $49 \pm 4$ & $0.52 \pm 0.17$ & $109 \pm 30$ & $0.24 \pm 0.08$ \\
& 30 & $58 \pm 4$ & $0.52 \pm 0.17$ & $100 \pm 24$ & $0.30 \pm 0.08$ \\
& 90 & $62 \pm 6$ & $0.54 \pm 0.17$ & $110 \pm 26$ & $0.31 \pm 0.10$ \\
ECAP & 0 & $38 \pm 3$ & $0.62 \pm 0.15$ & $71 \pm 12$ & $0.33 \pm 0.08$ \\
& 30 & $44 \pm 3$ & $0.65 \pm 0.14$ & $72 \pm 13$ & $0.40 \pm 0.09$ \\
& 90 & $47 \pm 4$ & $0.66 \pm 0.15$ & $75 \pm 10$ & $0.41 \pm 0.09$ \\
\hline
\end{tabular}

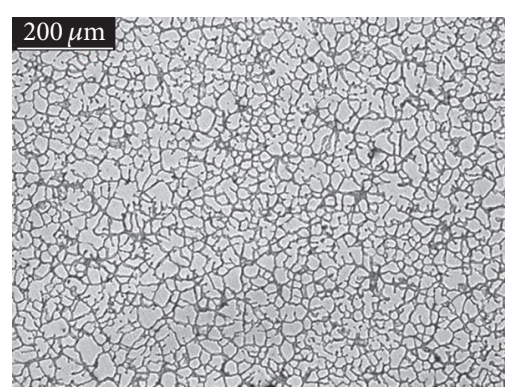

EMS

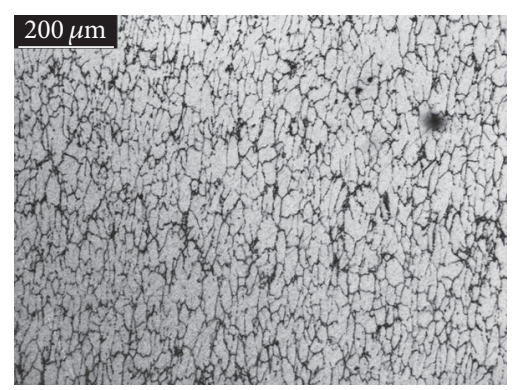

ECAP

FIGURE 3: Conventional B\&W metallography of the as cast $\mathrm{Al}-4.0 \mathrm{wt} \% \mathrm{Si}-2.5 \mathrm{wt} \% \mathrm{Cu}$ produced by EMS and after one ECAP pass.
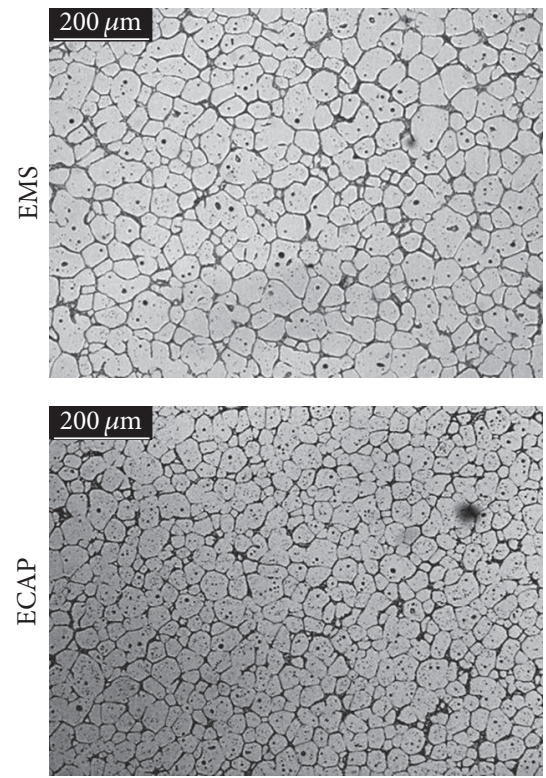

$0 \mathrm{~s}$
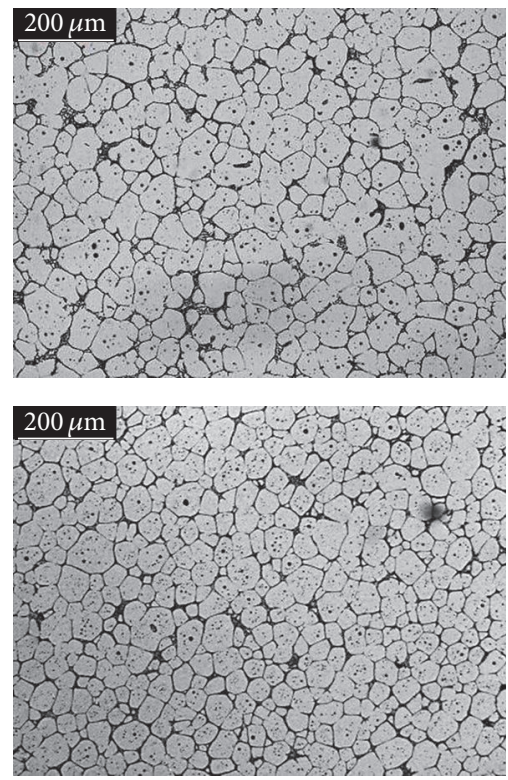

$30 \mathrm{~s}$
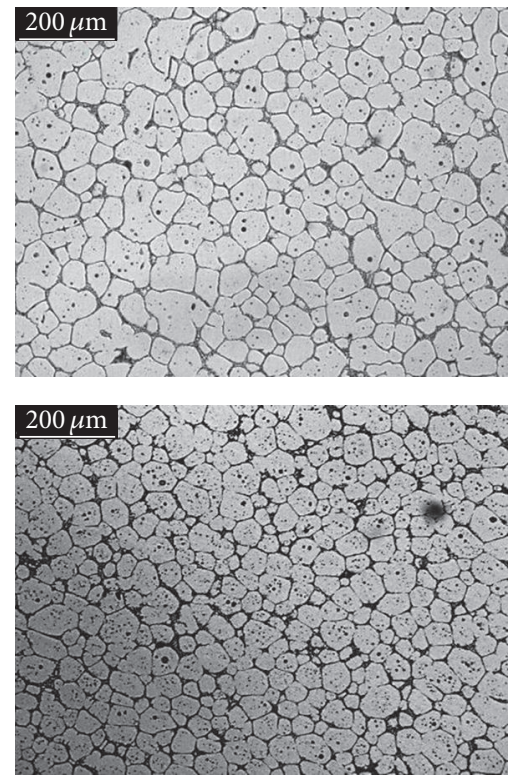

$90 \mathrm{~s}$

Figure 4: Conventional B\&W metallography of the EMS and ECAP samples heat treated at $584^{\circ} \mathrm{C}$ in which is expected to be $60 \%$ of solid fraction during 0,30 , and 90 s holding time, showing the morphology of the globules.

Table 3 shows a summary of the microstructural characterization in all tested conditions. The largest reduction in grain size (colour metallography) occurs with $60 \%$ solid fraction, where there was a reduction of approximately $40 \mu \mathrm{m}$. It is important to notice that the high solid fraction used in this paper facilitates the coalescence phenomena due to the contact amongst solid particles. And even with these phenomena, the material produced by electromagnetic stirring followed by the ECAP process can rearrange and distribute better during heating to the semisolid state.

The quantitative data presented in Figure 6 highlights the microstructural changes caused by reheating treatment in the condition of $60 \%$ solid fraction, at treatment times of 0,30 , and $90 \mathrm{~s}$, indicating the changes in globule size (Figure 6(a)), 

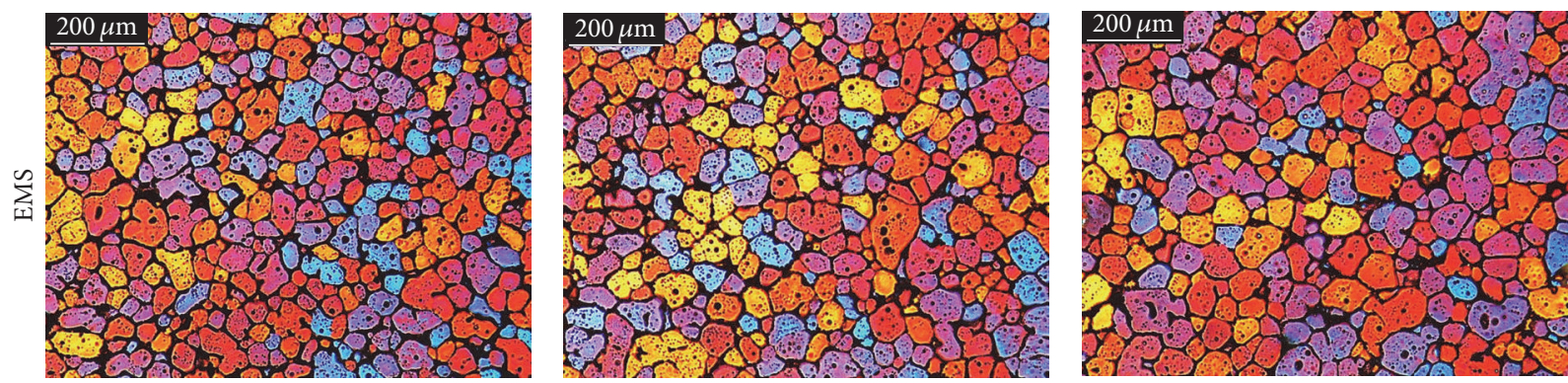

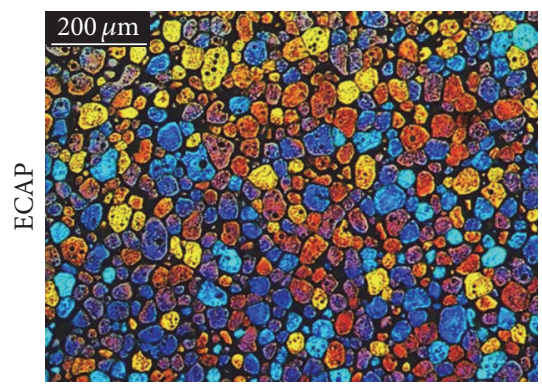

$0 \mathrm{~s}$

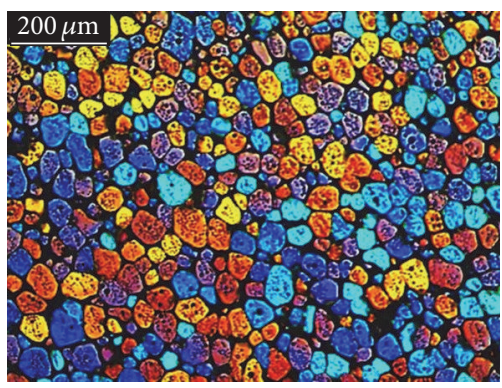

$30 \mathrm{~s}$

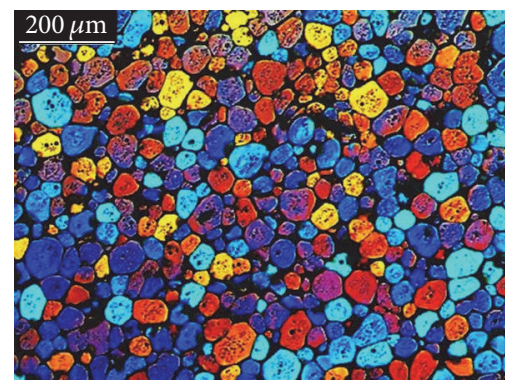

$90 \mathrm{~s}$

FIGURE 5: Polarized colour metallography of the EMS and ECAP samples heat treated at $584^{\circ} \mathrm{C}$ in which is expected to be $60 \%$ of solid fraction during 0,30 , and 90 s holding time, showing the morphology of the grain.

grain size (Figure 6(b)), circularity shape factor (Figure 6(c)), and the Rheocast Quality Index (Figure 6(d)) for the two processing routes tested.

As mentioned earlier, the samples produced by EMS showed increased globule size and grain size which was described in a previous paper [3]. The samples produced by ECAP samples showed significantly diminishing grain sizes. The recrystallization process, which precedes the semisolid stage in the ECAP route, caused small new grains to nucleate within the structure, facilitating their detachment during partial melting, resulting in very fine grains and homogeneous grains after solidification. The value of the shape factor $(\mathrm{SF})$ indicates the globular structure. In general, it can be noted in Figure 6(c) that the $\mathrm{Al}-4.0 \mathrm{wt} \% \mathrm{Si}-2.5 \mathrm{wt} \% \mathrm{Cu}$ alloy microstructure is globular with values above 0.60 . Figure $6(\mathrm{~d})$ shows the evolution of the Rheocast Quality Index in the samples after reheating treatment to the semisolid state. The RQI can be helpful in indicating good or poor rheological behaviour in terms of the microstructural features, because dividing the globule size by $x$ grain size, you have the rate for which it is expected that the value found is the closest to " 1 ," because in these conditions the grain size would be equal to globule size, a fact that would imply a less complex structure. The graphs in Figure 6 show that this varies little with heating procedure; for example, the results show that there were no significant differences in these parameters after the specimens were heated up to the semisolid state to achieve a solid fraction $60 \%$, indicating that the microstructure is highly stable, a characteristic that is in fact essential to ensure the thixoforming process can be controlled. Thus, among all the samples, the best combination of GS, GLS, and SF was achieved by the ECAP samples.

\section{Conclusions}

ECAP process is a promising route for production of semisolid raw material for thixoforming. Structure of the $\mathrm{Al}-4.0 \mathrm{wt} \% \mathrm{Si}-2.5 \mathrm{wt} \% \mathrm{Cu}$ alloy presented excellent response to the recovery and recrystallization mechanisms that lead to a refined microstructure ideal for thixoforming. Small globule sizes of about $45 \mu \mathrm{m}$ and small grain sizes of about $75 \mu \mathrm{m}$ and circularity shape factor higher than 0.60 were obtained. The alloy presented good morphological stability at the semisolid state without presenting significant changes in size and shape that should lead to homogeneous apparent viscosity and consequently homogeneous die filling. Comparing the two processing routes tested, the ECAP process yielded the most suitable thixotropic raw material, presenting the best results.

\section{Additional Points}

Highlights. The paper introduces new Al-Si-Cu alloys for thixoforming and morphological comparison of $\mathrm{Al}-\mathrm{Si}-\mathrm{Cu}$ alloys by electromagnetic stirring and ECAP.

\section{Competing Interests}

The authors declare that they have no competing interests.

\section{Acknowledgments}

The authors would like to thank São Paulo Research Foundation (FAPESP) Grants 2009/08478-1, 2013/09961-3, and 


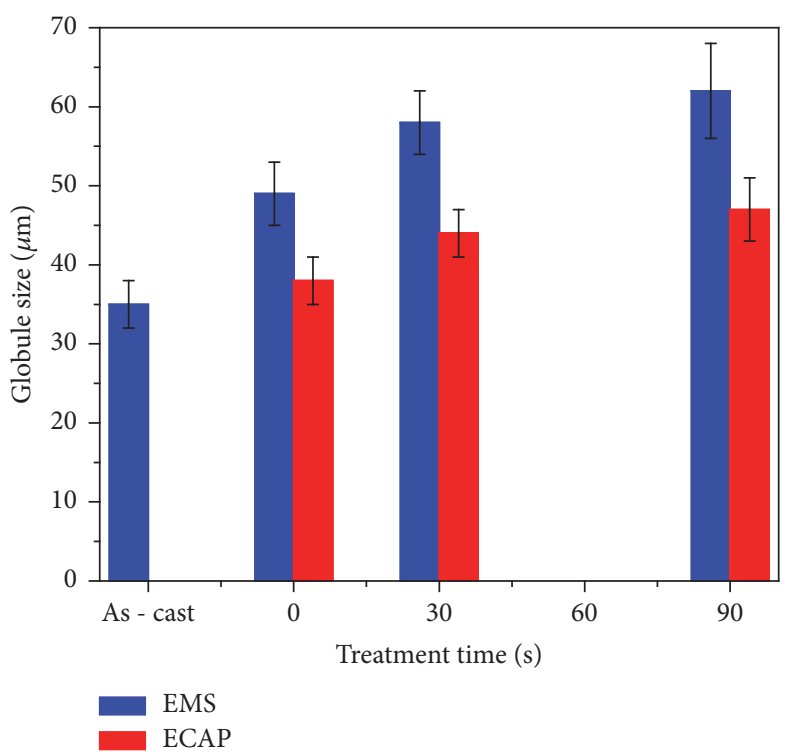

(a)

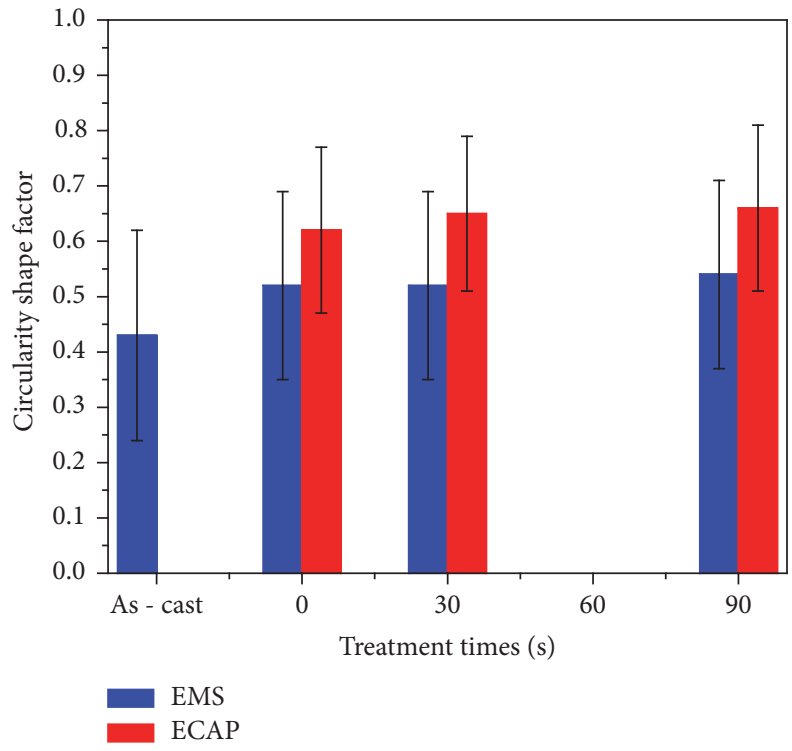

(c)

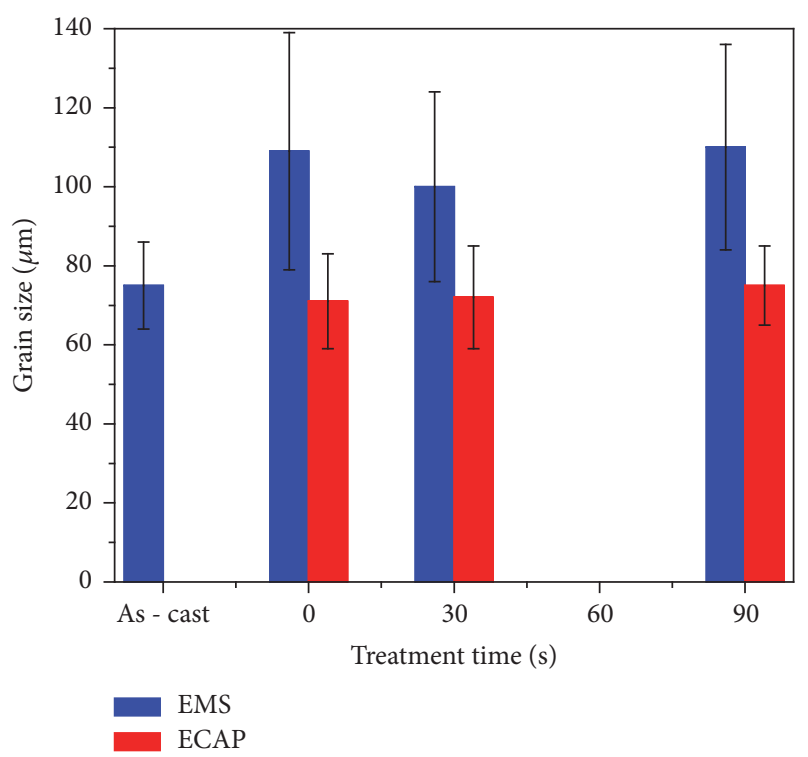

(b)

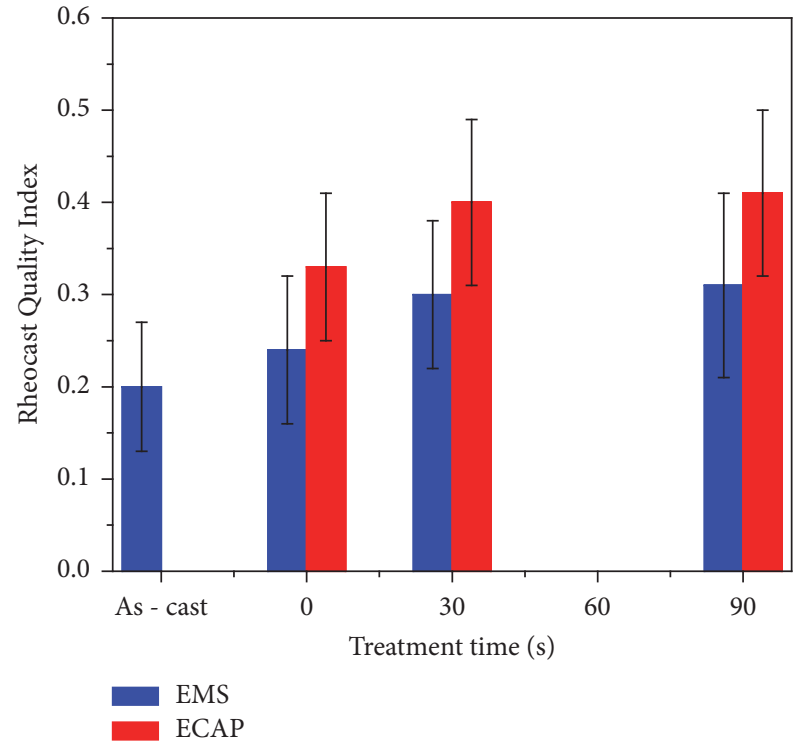

(d)

FIGURE 6: Globule size, grain size, circularity shape factor, and RQI of the Al- $4.0 \mathrm{wt} \% \mathrm{Si}-2.5 \mathrm{wt} \% \mathrm{Cu}$ samples alloy heat-treated (584 $\left.{ }^{\circ} \mathrm{C}\right)$ at $60 \%$ of solid fraction in 0,30 , and $90 \mathrm{~s}$.

2015/22143-3, National Council for Scientific and Technological Development (CNPq) Grant 306896/2013-3, and Coordination for the Improvement of Higher Education Personnel (CAPES) for financial support of this research. They would also like to thank the Faculty of Mechanical Engineering at the University of Campinas (UNICAMP) and Federal Institute of Education, Science and Technology of São Paulo campus Bragança Paulista (IFSP) for the practical support.

\section{References}

[1] M. C. Flemings, "Behavior of metal alloys in the semisolid state," Metallurgical Transactions A, vol. 22, no. 5, pp. 957-981, 1991.
[2] M. C. Flemings, R. G. Riek, and K. P. Young, "Rheocasting," Materials Science and Engineering, vol. 25, pp. 103-117, 1976.

[3] L. V. Torres and E. J. Zoqui, "Characterization of the microstructure and rheological behavior of $\mathrm{Al}-4 \mathrm{wt} \% \mathrm{Si}-2.5 \mathrm{wt} \% \mathrm{Cu}$ alloy produced by direct chill casting and electromagnetic stirring," Solid State Phenomena, vol. 192-193, pp. 142-148, 2013.

[4] C. Vives, "Elaboration of semisolid alloys by means of new electromagnetic rheocasting processes," Metallurgical Transactions $B$, vol. 23, no. 2, pp. 189-206, 1992.

[5] C. Limmaneevichitr and W. Eidhed, "Fading mechanism of grain refinement of aluminum-silicon alloy with Al-Ti-B grain refiners," Materials Science and Engineering A, vol. 349, no. 1-2, pp. 197-206, 2003. 
[6] E. Tzimas, A. Zavaliangos, and A. Lawley, "The effect of microstructure on the rheological properties of alloys in the semisolid: a comparison between MHD, SIMA and spray cast alloys," in Proceedings of the 5th International Conference on Semisolid Processing of Alloys and Composites, pp. 345-352, Godlen, Colo, USA, 1998.

[7] G. Yan, S. Zhao, S. Ma, and H. Shou, "Microstructural evolution of A356.2 alloy prepared by the SIMA process," Materials Characterization, vol. 69, pp. 45-51, 2012.

[8] V. M. Segal, "Materials processing by simple shear," Materials Science and Engineering A, vol. 197, no. 2, pp. 157-164, 1995.

[9] K. N. Campo, C. T. W. Proni, and E. J. Zoqui, "Influence of the processing route on the microstructure of aluminum alloy A356 for thixoforming," Materials Characterization, vol. 85, pp. 26-37, 2013.

[10] L. V. Torres, D. M. Benati, and E. J. Zoqui, "Morphological evolution of $\mathrm{Al}-2 \mathrm{wt} \% \mathrm{Si}-2.5 \mathrm{wt} \% \mathrm{Cu}$ alloy produced by EMS and EMS enhanced by ECAP," Solid State Phenomena, vol. 217-218, pp. 105-110, 2014.

[11] C. T. W. Proni, L. V. Torres, R. Haghayeghi, and E. J. Zoqui, "ECAP: an alternative route for producing AlSiCu for use in SSM processing," Materials Characterization, vol. 118, pp. 252262, 2016.

[12] NADCA, Product Specifications Standards for Die Castings Produced by the Semi-Solid and Squeeze Casting Processes, 2009.

[13] E. J. Zoqui, "Morphological analysis of SSM Al-4.5 wt.\% Cu measured by the rheocast quality index," Journal of Materials Processing Technology, vol. 143-144, no. 1, pp. 195-201, 2003.

[14] E. J. Zoqui, D. M. Benati, C. T. W. Proni, and L. V. Torres, "Thermodynamic evaluation of the thixoformability of Al-Si alloys," Calphad, vol. 52, pp. 98-109, 2016. 

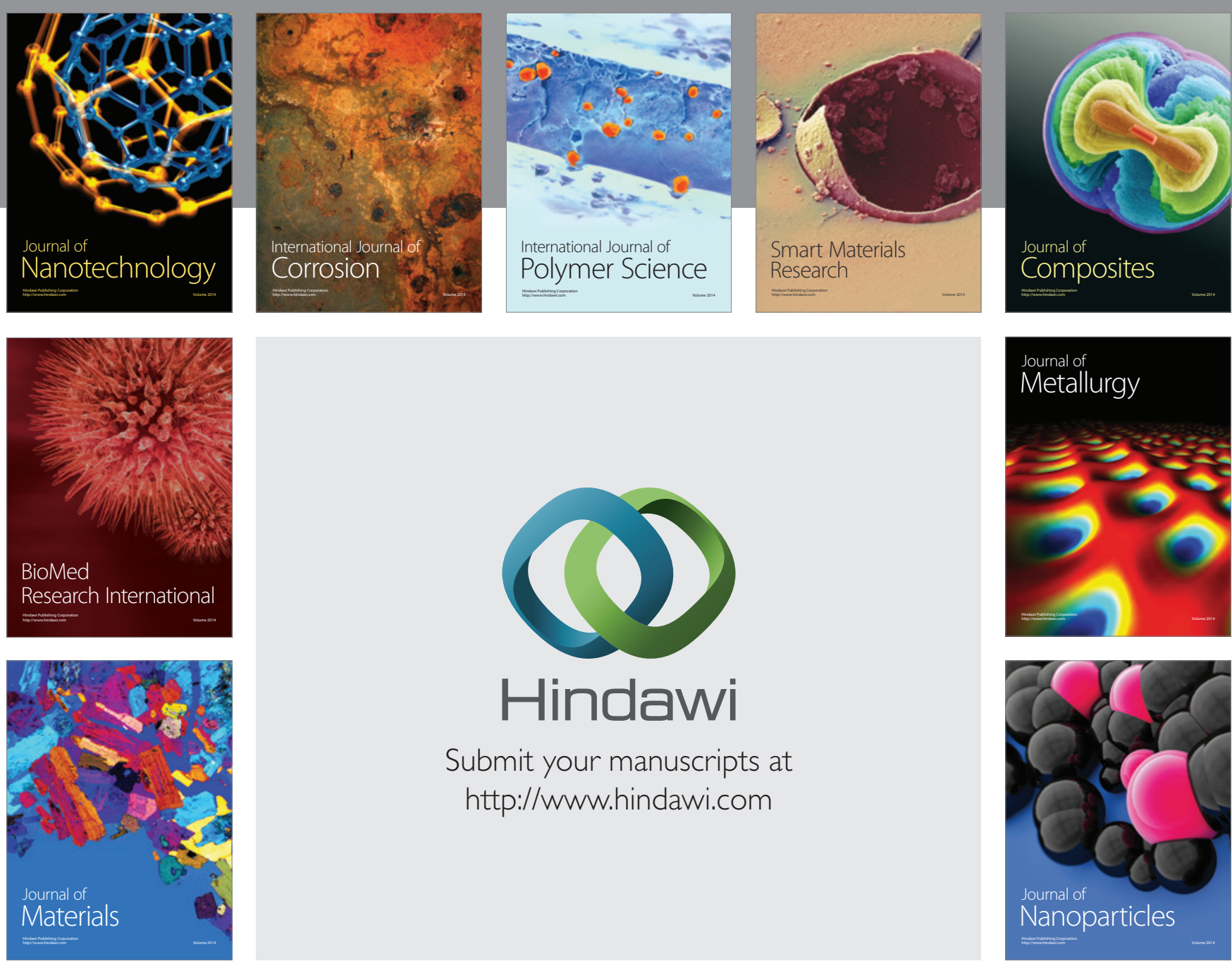

\section{Hindawi}

Submit your manuscripts at

http://www.hindawi.com

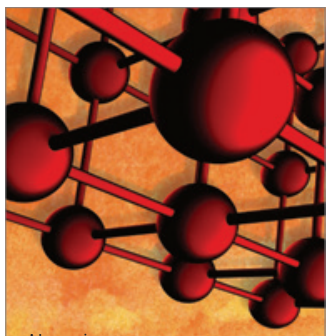

Materials Science and Engineering
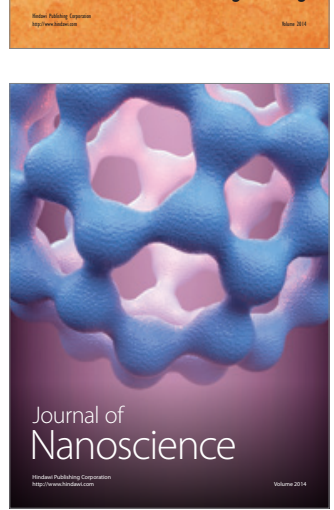
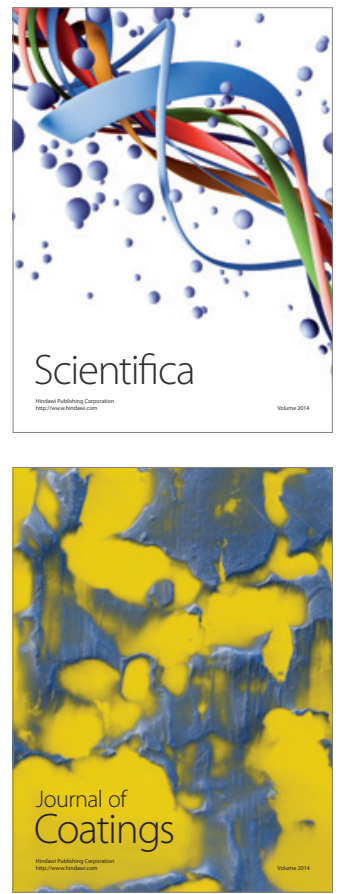
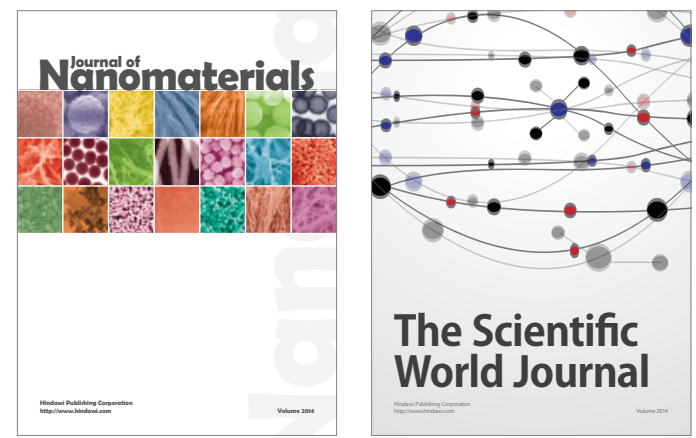

The Scientific World Journal
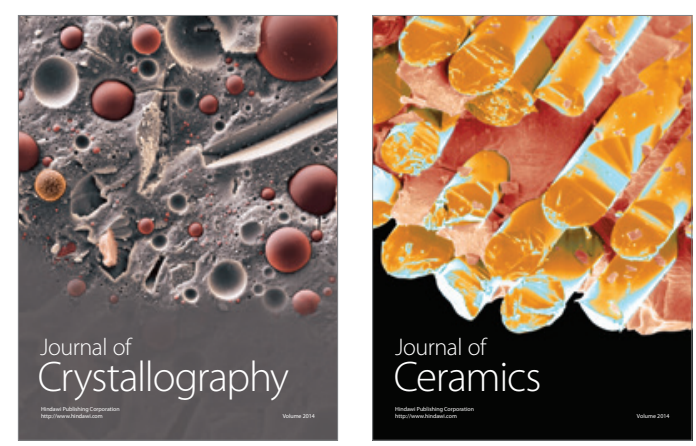
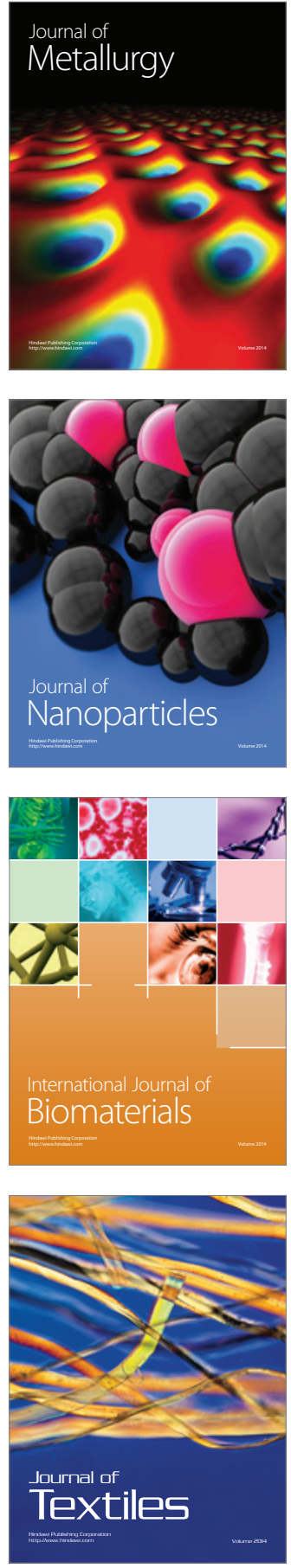